\title{
Marriage Discord and Social Media Platforms among Couples: A Case Study of One Selected High-Density Suburb in Marondera, Zimbabwe
}

\author{
FLORENCE JURA* \\ Zimbabwe Open University, Student Management Unit, Harare Chitungwiza Regional Campus, P.O. BOX \\ MP1119 Mount Pleasant, Harare, Zimbabwe
}

*Corresponding Author: FLORENCE JURA, Zimbabwe Open University, Student Management Unit, Harare Chitungwiza Regional Campus, P.O. BOX MP1119 Mount Pleasant, Harare, Zimbabwe

\begin{abstract}
This case study was conducted in Marondera Peri Urban areas in Mashonaland East Province with the aim of ascertaining the link between marriage discord and social media platforms use. The research adopted an interpretivist research philosophy and a qualitative research approach with which case study research design was used. Data was generated through in-depth interviews using purposive sampling. The targeted population were couples in Elesmwood Park in Marondera, Mashonaland East Province. The study established that most issues of marriage discord emanated from social media platforms. A good number of the participants also mentioned that there was no bond creation between couples as much time was wasted on social platforms causing couples to drift apart thus leading to marriage discord.Findings also reveal that social media played a part in family members` decisions making as people tended to make decisions based on peer influence, attitudes, and beliefs as that which is socially acceptable. Another problem with social media was that couples were spending a lot of time on social media meant less time to bond with the children and the family. However, some participants were positive about the benefits of social media when used by the families as the platforms were cheap for long distance communication. From these findings, it was recommended that....
\end{abstract}

Keywords: Marriage discord, social media, couples, high-denstiy

\section{BACKGROUND To THE STUDY}

There have beenever-increasing reports of divorce cases, most notably as reported in newspapers in Zimbabwe as well as court cases capitulated with global addiction to social media and its influence in the livelihood of humanity. A Boston University study carried out in 2014 concluded that Facebook is a significant predictor of divorce rate and spousal troubles in the United States. The results of the study showed that married who use Facebook were 32\% more likely to leave their spouse. This may be the result of that the social media provides too much freedom of expression and opinion that results in conflicts and finally dissolution of marriage (Besley and Chadwick 1992). In Italy, Halfens on twitter (www.twitter.com/@Jimhalfens) reports that Ettore Gassani, a divorce lawyer told The Times of London that $40 \%$ of adulterous divorce cases in Italy cite WhatsApp messages as evidence of unfaithfulness, thus social media has boosted betrayal in Italy.Elphinston and Noller (2011) reported that a website called AshleyMadison.com even caters for married people looking for affairs. Its statistics are that over 130 million people worldwide visit the website every month. The result will be hooking up with a casual partner and this will bring disharmony in the home.The Standard newspaper of 15 December 2013 reported of a couple who divorced because the wife stumbled upon some WhatsApp texts that bore her husband's infidelity with a high school sweetheart whom he had reconnected with on Facebook. The wife blamed technology for bringing up social media that has destroyed her marriage. From the same article social commentator Amai Chisamba commented that most marriages are breaking up due to social media because partners fail to identify what is good from what is bad regarding social media use.

Based on this background, it follows that there is a great need to advance scholarship in this area and establish the circumstances surrounding the marriage discord and social media. 
Marriage Discord and Social Media Platforms among Couples: A Case Study of One Selected HighDensity Suburb in Marondera, Zimbabwe

\section{Statement Of The Problem}

The increasing number of divorce cases has led to marriage discord.

\section{RESEARCH QUESTIONS}

1. How does social media use influence divorce?

2. How is the decision-making process influenced by the use of the social media in marriage?

3. In what ways does social media use compromise parental roles in marriage?

4. What are the benefits of social media use in families?

5. Which may be the possible solutions to counteract the influence of the social media on marriages?

\section{REVIEW OF EMPIRICAL STUDIES}

\subsection{The Influence of Social Media on Marriages}

A study on social media use carried out in the USA in 2008 as produced by the journal of Cyber psychology, behaviour and social networking concluded that according to $15 \%$ of people in the USA, social media is dangerous to their marriages while, 16\% pointed Facebook as causing marriage discord. It stated that regular users of Facebook, "experience Facebook-related conflict with their romantic partners. The American Academy of Matrimonial Lawyers released a report in 2005 (Cacioppo and Patrick 2008), which revealed that a third of all divorce filings contain the word Facebook. A lot of those filing papers refer to an online relationship. Some husbands or wives have even declared their intention to break up through Facebook, e-mail, twitter, or Instagram. The above studies and reports reveal that there are a high number of divorce cases perpetuated by use of social media. Norah (2015) points out that such high numbers of divorce usually emanate from time wasted by a partner on social media including liking of pictures of other probably nude/beautiful ladies or handsome pictures which result in negative comments comparing with one's marriage partner. However, the above study may be subject to debate as it was carried out in a more developed country where probably there is advanced privacy, respect between spouses, and respect of one's property. The Zimbabwean context may pose a different outcome because of its cultural and technological background where customarily there is no respect of one's privacy in marriage. However, there is now a law that safeguards the privacy of partners though this law may be respected by a few.A more practical approach will be to reveal the Zimbabwean context itself. An extract from the Standard Newspaper of 15 December 2013 reports that The High Court of Zimbabwe statistics indicate an increase in the number of divorce cases. In 2011, the High Court received 1551 divorce cases, a $21 \%$ increase from the 1216 cases lodged in 2010. In 2008, the Harare Civil Court dealt with 427 child maintenance cases and the figure rose to 2174 in 2010 and around 4000 in 2011 . It is believed that the bulk of the cases were caused by disputes arising from social media use. The H Metro newspaper of 6 March 2017 reveals how a couple ended up in divorce because of discovery of cheating messages through Whatsapp where the husband discovered messages that showed an adulterous affair by his wife. Another challenge brought about by social media use in marriage as posited by Alsharkh (2012) is the risk of reconnecting with ex-partners. Alkead (2013) brings out that the social sites bring a reconnection with ex-lovers and it might be easy to get back on track. Such flirting results in conflicts in the home if it is discovered. Alsharkh's study in India revealed that it is quite common to have reconnections with ex-lovers and rekindling the love resulting in marriage discord. However, it is also important to note that the Indian culture highly advocates arranged and forced marriages, and this may be a pushing factor in reconnecting with the ex-lover. What waits to be seen now is what can cause the reconnection and resultantly conflicts in the married families.Another way Facebook can have a devastating effect on marriages as commented by Kalish (1994) is by enabling so many easy ways to flirt online. Users can "like" statuses, "like" pictures, "like" comments, poke another user, send them gifts, comments their wall, comment their statuses, comment their pictures, and send private messages. Of course, some of these (such as the "liking" of a comment or status) can be innocent enough and may not be flirting at all.

\subsection{Social Media Use and Behaviour Change in Marriage}

Messaude and Alaeede (2012) commented that the social media allows to connect with more people therefore there is great room to be side swerved from views of others when in a comprehensive 
situation. The fact that the social media is not ethically bound, anyone can send anything, and it leaves the one seeking for advice to select what best suits them (Paris 2012).Morgaine (2001) propounds that social media contagion effect. They explain that behavior plays a great part in influencing decision making. A friend who posts a message about their bad moral probably from a suspicion of a cheating partner may result in the next friend to also vent that anger on spouses. This contagion effect is a result of generalization effect (O'Keefe and Claris Pearson 2011). That can result in conflicts in the marriage as some kind of stereotyping would have developed.The other 'disease' that emanates from social media use and influences behavior change is comparing oneself with others whom one chats with. Alshark (2013) supports the above assertion stressing that most people want to be like what their peers are like. Sharing posts on dress codes, night outs may influence how one looks at their marriage. A study carried by John Cacioppo in (2009) revealed that quite several people adore what they think is freedom in their other associates and that can have consequences on their being. For example, one who is bound at home with their partner may eventually prefer going out at night with other friends because they also do it at their home and so are free.

Holt, Smith and Layton (2010) points out that some people do not have control on what to share on their social sites. Cohen (2004) posits that the habit of going on social media after a disagreement is very common in marriages of today leading to marriage discord. People have the habit of going on Twitter, Facebook and other social media sites and expressing whatever they have in mind. It is very easy to turn to social media for comfort and distraction when there is a tension or storm in a relationship. At that tense moment, one may post some nasty and unpleasant remarks which they may regret later. One might even get depressed by all the posts and pictures of the adorable couples out there. One might even be lured to look for a better relationship rather than putting extra effort to work things out with their spouse.Comparing your spouse with another's spouse, or your own family dynamic to your endless social media friends' family dynamics through posted images, can cause long-lasting relational and emotional detachment from your own spouse and family.

\subsection{Social Media and Parenting}

Ralston (2012) posits that it is not only what a person does on social media, but also how much time they spend doing it that can create conflict. Excessive time spent on social media has been shown to negatively impact parent-child relationships in that there will be lack of attention to the child. Ralston (2012) further pointed out that children need eye contact when communicating with them and so if a parent is always on the phone, they may respond to the needs of children without paying $100 \%$ attention and the children will feel neglected. This may result in the child getting close to those who will be giving them enough attention. To add to this Turner (2011), brings out that lack of attention to children when they are playing can result in injuries that could have been prevented by the parent who is deeply engrossed in browsing on their phone or computer. The other impact that social media use has on parenting as pointed out by Ray and Jat (2010) is that family time has been seen to deteriorate. They pointed out the example that dinner time is time for the family to discuss family issues or sharing their day's experiences. However, this may not be as members may be busy on their gadgets, perusing social sites and not associating physically with their family members. This, therefore, results in marriage discord.

Control of social media use in children is seen to be very essential by Huisman (2014) as it does not control children on what to know and what not to know. Children at different levels are controlled on the knowledge to acquire in authoritarian parenting system. However, the social media does not have such limits and so children are exposed to language and information that may not be age appropriate. Ralston (2012) concur with the above assertion when he authored that some parents become surprised to hear their children talking in languages, they have not taught them before and some of it being vulgar or socially unethically accepted. This may result in some parents stalking their children to see and direct the social sites they visit. However, as moved by Turner (2011) stalking may result in both parents and children developing a sense of mistrust on one another, thus creating conflict of interest.

\subsection{Benefits of Social Media to Families}

According to Fernandez (2011), the use of the social media brings parents and childrencloser. Communication is made quick and easy, and the fatherly or motherly touch is felt by the children 
when they communicate with their parents and sharing pictures as well. Thus, the distance will seem to have been reduced. Another way in which the use of the social media is seen to bear fruit in families is that parents can apprehend their children's access to social media as a way of grounding them if they have not adhered to family rules which may require some punishment. Since the children will need to communicate with their peers, the apprehension of their computers or phones will help guide them to confine with set rules.Kalish (1994) also supports that the social media has brought positive ideas in parenting by expressing that it is a learning platform for parents. When parents post events in their families and how they enjoyed them say school visits, birthdays or attending to their children's community performances, other parents feel encouraged doing the same and hence their parenting practice will improve, and this will strengthen the family relationship. More so, parents post information on challenges they may be facing with their children and seek advice from others via social media. If the advice is positive and helpful, then the social media use will have proved it is worthy.

\subsection{Possible Solutions to Counter the Influence of Social Media on Marriage}

Bancher (2011) sets it straight that one should set goals or guidelines on how they use the social media. One should not become a servant of the social media but should be seen to control it. Beneficial ethical social sites are the most websites to visit as they do not have dirty influence on even our general life. Alkead (2013) is also of the idea that there is need to limit the time one spends on social network. One should not let social media steal every moment of their marriage relationships. Moreover, limiting time spend on social networks will limit the rate of suspicion of cheating or hiding information from one's partner, hence building trust in the marriages. Norah (2015) stated that there is great need to maintain a balance between your online and offline life. This, however, is said to minimize marriage discord in relationships. This calls for a level of equilibrium between visiting online websites and attention to all other activities that require the same or more than attention. As the Social learning theory states that behaviour is learned and can be unlearned (Bandura 1986) it is quite beneficial for social media users to change their behaviour so that focus is put on their families and minimise marriage discord. It is also important to monitor one's own emotions and reactions without being influenced by others. Moraine (2001) sees this as counter to the social media contagion effect previously. Explained A friend's bad mood should not affect your mood as well. It is alluded that all marriages have their challenges. What makes a good marriage is how one responds to those challenges.

\section{RESEARCH METHODOLOGY}

The study adopted the interpretivist philosophy and the qualitative approach. The case study design was used, and data was collected using interviews and focus group discussions. The participants were asked to provide information on social media platforms and marriage discord.Mays and Pope (2000) further argue that the interpretive paradigm creates an environment where interpretations are open to reinterpretation and negotiation through the conversation. on the other hand, Dempsey and Dempsey (1996) note that the case study method has strength in investigating the present status of a phenomena. Data was also generated from the various face to face interviews conducted. Tables were used to present the responses from the research participants in a manner that was easy to interpret.

\section{Population And SAMple}

Bowen (2009) refers to the population as an aggregate or totality of the objects, subjects or members that conform to a set of specifications. It is all the individuals in whom we are interested in carrying out the research. The population of Elesmwood Park is estimated at forty-six thousand four hundred. However, the research considered seven couples to participate in the research process. The age range of the couples was between 18 years and 35 year as it is assumed that persons in these age groups are active on social media platforms.

\section{Data Collection Method}

The researcher explained the importance of carrying out the research study since the onset of the research study. This was done to guard against the ethical considerations, for example keeping participants information in confidence and informed consent which are key in research. Appointments were done through the WhatsApp platform which was created for the research purposes. Participants were always kept abreast with the research progress. 
Marriage Discord and Social Media Platforms among Couples: A Case Study of One Selected HighDensity Suburb in Marondera, Zimbabwe

\section{Presentation And Discussion Of Results}

Data collected was prepared and checked for accuracy in terms of relevance of responses to the research study. The data from the interviews and focus groups will be presented as descriptive reports. Comments will then follow in line with the research questions layout.

\subsection{Demographic Distribution of Participants}

The participants consisted of seven females and seven males. Altogether they were fifteen.The participants are identified by numbers. Participants 1-7 participated in the in-depth interviews and 814 participated in the focus group discussion.

Table1. Distribution of participants by age $(N=14)$

\begin{tabular}{|l|l|}
\hline AGE RANGE & NUMBER OF PARTICIPANTS \\
\hline $18-22$ & 3 \\
\hline $23-26$ & 4 \\
\hline $27-30$ & 3 \\
\hline $31-35$ & 4 \\
\hline
\end{tabular}

Table 1shows that the age range 23-26 and 31-35 had most participants while age ranging 18-22 and 27-30 had equal participants three in each category.

Table2. Educational background of the participants.

\begin{tabular}{|l|l|l|l|}
\hline Level & Ordinary & Advanced & Tertiary \\
\hline Participants & 5 & 2 & 7 \\
\hline
\end{tabular}

The above table shows that five participants attained Ordinary Level, two attained Advanced Level and seven attained Tertiary Education. The researcher chose to have participants of various levels of education as replica of a normal community system.

\subsection{Influence of Social Media on Decision Making in Families}

Data collected from the interviews and the focus group discussion showed that social media played a part in family members' decisions making. Some of the responses to support this claim are as follows:

Participants 4 and 7: People tend to make decisions based on peer influence, attitudes, and beliefs as that which is socially acceptable.

Participant 2: At one time I did not trust my husband when he frequently came home late and drunk. I felt he was cheating on me, so I posted that on a certain platform on Facebook called Kuzeyadzerudo.

Participant 11: My wife felt I was not doing enough to her when she would see and receive messages from her friends of their 'bling bling' social activities. This brought endless quarrels and threats of dissolving the marriage. We finally resolved this by engaging a marriage counsellor.

Participant 14: Sometimes, after discovering a cheat some partners feel so betrayed that they may decide to kill the cheating spouse and end up in jail for murder or they will commit suicide to do away with the crime.

Participant 9: Suppose it is a wife who has been discovered cheating through social media and the family has kids, the husband might even decide to disown the children since he may feel the children might not be biologically his. Kunyangwehamadzangu in such a situation dzinogonakutongof ungawosekudaro and put pressure on me to disown the children.

\subsection{Social Media Use Versus Parental Roles}

The responses were as follows:

Participants 1, 3 and 4: Spending a lot of time on social media means less time to bond with the children.

Participant 4: More time on social media can eventually lead to a parent missing out on such issues as noticing change in behaviour that may even result from abuse.

Participant 7: Social media deteriorates family time and weakens the bond of family association especially as exhibited by teenagers who may miss important family time such as dinner as they will be busy with their social media gadgets. 
Participant 5: My husband goes to work and spends the whole day there. When he comes back, he does not have time with kids, even helping homework, hid much time is spend on Facebook.

These responses show that working spouses are mostly the ones who spend less time with their children because when they are back from work, they become busy on social media.

Participant 6: My son engaged in early sex and impregnated his classmate at form 3. we then agreed with the girls to take care of the children while she goes back to school. Now she enrolled at another school.

Probably, it is because the child did not have parental control because the mother is not always home since she is a cross boarder trader.

Participant 11: At our school we have had several incidents where learners abuse the internet services. Instead of them using it for educational purposes you find these teenagers busy on social sites that are not educative, hence the reason we have increased teenage pregnancies and early marriages as well as increased rates of drug abuse that have caused school dropouts.

Participant 11: There are pathetic situations we witness at school where some learners' life takes a sudden downfall because their father is now supporting another family. The learners will face challenges in fees payment, shortage of learning materials and even food especially in situations where the mother will be a full-timehousewife where she may have no means to earn a living.

The above participant is a facilitator so, he is well acquainted with behaviour of learners and the challenges they face.

Participant 9: It is very difficult to take care of non-biological children who maybe does not belong to you, because there will be not bond at all.

Participant 10: When there is a divorce; it is not only the children who suffer but the surrounding family members as well as the community at large. In-laws will no-longer receive the support they would have been receiving before and that becomes another challenge to them.

The two participants above agreed that divorce negatively impacted on dependents.

\subsection{Benefits of Social Media Use in Families}

From the findings, most participants were positive about the benefits of social media when used by the families. For example, the following responses help to support this assertion:

Participants 6 and 13: Social platforms are cheap for long distance communication.

Participant 7: It is easy for children who live away from their parents especially those whose parents live out of the country to be close even through sharing of pictures and videos or via Skype where the element of physicality is enhanced.

Participant 8: Social media promotes acquisition of ideas especially on parenting from other parents.

Participant 10.Promotes awareness of threats to the well-being of children especially on issues related to abuse and offers the immediate solutions.

Participants 7 and 14: Creation of family groups especially on WhatsApp enhances communication among family members.

Participant 11: Children can learn and easily communicate with their peers and assist one another in their homework and assignments on platforms.

The above responses show that social media was a very cheap way of communicating and was also a platform being used for acquiring knowledge.

\subsection{Possible Ways to Address the Negative Influence of Social Media Use.}

Participant1. It important that we have a single account which is free to everyone to avoid private associations. 
Marriage Discord and Social Media Platforms among Couples: A Case Study of One Selected HighDensity Suburb in Marondera, Zimbabwe

Participants 2, 7 and 14: It is good to discuss issues when couples face challenges in their marriages or seek counselling from professional counsellors. It is also good to seek advice from community elders.

The participants above may be from the same set up where they valued the traditional systems of seeking advice where elders were consulted.

Participant 11: Set your goals for social media usage and stick to them.

Participants 7 and 8: There is need for parental guidance on social media use by children and blocking harmful sites.

Participant 14: Discuss as a family the effects of social media and how to live with it without bringing disharmony.

Participant 9: The government must implement strict cyber laws that prohibit the sending of socially unaccepted content such as pornography and nudity.

\subsection{Effects of Social Media Platforms on Marriages}

According to most of the participants, social media platforms had negatively impacted on marriages. For example, three participants indicated that marriages were breaking and some always have tense and discorded relationships which at the end of the day couples are living in storm. There is no definite future for those relationships. Participants in the study also highlighted that social platforms had created hatred between couples such that they did not cherish social platform as partners spent most of their time on social media at the expense of all family members. Some of the participants also mentioned that there was no bond creation between couples as much time was wasted on social platforms causing couples to drift apart thus leading to marriage discord.

\subsection{Benefits of Social Media Platforms in Families}

Results indicated that social media platforms played a role in keeping families connected. Distance relationships were positively maintained through the social medial platforms. Social media had also brought about a revelation especially this time where COVID-19 pandemic had become rampant, globally. Learners were using these platforms for learning purposes and it was also cheaper than travelling around for education purposes. Thus, as according to the theory of Reciprocal Determinism, people could manipulate the environment for their own good (using the social media to benefit them).

\subsection{Possible interventions}

As singled out by one of the participants, one should not let social media steal every moment of their relationships. This entails limiting time spend on social networks which then limits the rate of suspicion of cheating or hiding information from one's partner. In other words, it brings trust in the family. In support, Alkead (2013) argues that there is need to limit the time one spends on social network. Comparing oneself with others should be limited or should not be allowed room to influence decision making (Boyd \&Edinson 2013). This entails that one should not be swayed by the status of others who they chat with. The focus should be on building one family. This is supported by Bancher (2011) who advocates for setting goals or guidelines on how to use the social media. Some participants indicated that users should not become servants of the social media but should be seen to control it. One of the participants recommended that beneficial ethical social sites were the websites to visit most as they did not have negative influence one`s general life. Couples needed to allow time for themselves considering that some spent time at work. Participants in the study highlighted that at times it was good to keep a distant from their spouses`cellphones as this triggered marriage discord. Keeping themselves busy all the time would also make couples live a happy life. Added to that, some participants were of the view that engaging in educational programmes was cited as another possible intervention strategy because there would it important that we have a single account which is free to everyone so as to avoid private associations.

Participants 2, 7 and 14: It is good to discuss issues when couples face challenges in their marriages or seek counselling from professional counsellors. It is also good to seek advice from community elders.

The participants above may be from the same set up where they valued the traditional systems of seeking advice where elders were consulted. 
Marriage Discord and Social Media Platforms among Couples: A Case Study of One Selected HighDensity Suburb in Marondera, Zimbabwe

Participant 11: Set your goals for social media usage and stick to them.

Participants 7 and 8: There is need for parental guidance on social media use by children and blocking harmful sites.

Participant 14: Discuss as a family the effects of social media and how to live with it without bringing disharmony.

Participant 9: The government must implement strict cyber laws that prohibit the sending of socially unaccepted content such as pornography and nudity.

\section{MAJOR Findings Of THE StUdy}

The following were the major findings of the study:

- Social media played a part in family members` decisions making as people tend to make decisions based on peer influence, attitudes, and beliefs as that which is socially acceptable.

- Spending a lot of time on social media meant less time to bond with the children and the family.

- Some participants were positive about the benefits of social media when used by the families as the platforms were cheap for long distance communication.

- Creation of family groups especially on WhatsApp enhances communication among family members.

- Some participants also highlighted that social platforms had created hatred between couples such that they did not cherish social platform as partners spent most of their time on social media at the expense of all family members.

- A good number of the participants also mentioned that there was no bond creation between couples as much time was wasted on social platforms causing couples to drift apart thus leading to marriage discord.

10. CONCLUSION

This study focused on the evaluation of marriage discord and social media in Elesmwood Park in Marondera, Mashonaland East Province. The motive behind carrying out the study was embedded in the belief that social media platforms have a negative impact on marriages, hence a marriage discord However, the research study showed mixed feelings social media platforms.

- Literature reflects that social media platforms have an impact on marriages, positive and negative.

- Social media is of much significance in that it keepsday to day life of distance relationships.

- Social media platforms such as Facebook, WhatsApp and twitter have caused marriage discord in relationships. This does not see boundaries, but the impact is across the board.

- The government must implement strict cyber laws that prohibit the sending of socially unaccepted content such as pornography and nudity.

- The study recommends that couples have time for each other to capture marriage discord.

\section{REFERENCES}

[1] Alsharkh, Y. (2012). The social media effect on the families of the Saudi society from the perspective of the youth. ASU Libraries. Retrieved from: repository.asu.edu/items/14718

[2] Bandura, A. (1986). Principles of behaviour modification. New York: Holt, Rinehart and Winston.

[3] Bauchner, H. (2011). Benefits and risks of social media use in children and adolescents.

[4] Bowen, G. A. (2009) Document Analysis as a Qualitative Research Method. Qualitative Research Journal, 9(8), 27-40.

[5] Boyd, D. \& Ellison, N. (2013). Sociality through social network sites. The Oxford Handbook of Internet Studies. Oxford: Oxford University Press.

[6] Cacioppo, J.T., \& Patrick, B. (2008). Loneliness: Human nature and the need for social connection. New York, NY: Norton. 
Marriage Discord and Social Media Platforms among Couples: A Case Study of One Selected HighDensity Suburb in Marondera, Zimbabwe

[7] Cohen L., Manion, L. and Morrison, K. (2007) Research Methods in Education (6 ${ }^{\text {th }}$ Ed.). London: Routledge-Falmer Publisher's Companion website

[8] Cohen, S. (2004). Social Relationships and Health.American Psychologist, 674-84.

[9] Fernández, A. (2011).Clinical Report: The impact of social media on children, adolescents and families.Archivos de Pediatría del Uruguay, 82(1), 31- 32.

[10] isman, S. (2014). Parent connection: Media in the home with young children. Childhood Education, 90(2), 159-160.

[11] Kalish, N. (1994).Lost and Found Lovers: Facts and Fantasies of Rekindled Romances. Thriftbooks,

[12] Mele, C., Pels, J \&Polese, F. (2010).A Brief Review of Systems Theories and Their Managerial Applications. Service Science 2(1/2), 126 - 135.

[13] Miles, M. B., Huberman, A. M.\&Huberman, M. (1994). Qualitative data analysis: An expanded sourcebook. Thousand Oaks, CA: Sage Publications.

[14] Morgaine, C. (2001). Family Systems Theory. CFS 410U.

[15] Paris, F. (2012, July 30). Twitter reaches halfa billion accounts more than 140

[16] Patton, M. Q. (2002). Two decades of developments in qualitative inquiry: A personal, experiential perspective. Qualitative social work, 1(3), 261-283.

[17] Rukuni, M. (2002) Qualitative Research Designs in Conflict. Harare: Zimbabwe Open University.

[18] Saunders, M., Lewis, P. \&Thornhill, A. (1997).Research Methods for Business Students. Pitman Publishing, London.

[19] Silverman, D. (2000). Doing qualitative research: A practical handbook. Thousand Oaks, CA: Sage Publications.

[20] Turner, F. (2011). Social work treatment: Interlocking theoretical approaches (Fifth Edition). New York: The Free Press.

[21] Wijeyadasa, R. (2000). Media freedom and responsibility. New York, NY: Routledge.

\section{AUTHOR's BIOGRAPHY}

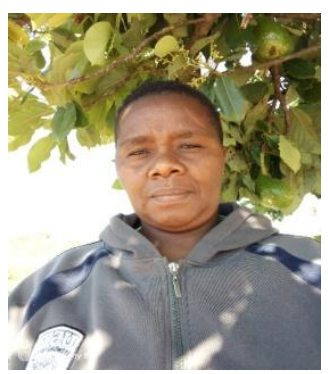

Ms Jura Florence, is a Student Advisor in the department of Students Management at Harare/Chitungwiza Regional Campus. She has 20 years experience working with students in different departments, Academic Registry, Centre for Students Management and Department of Counselling. She holds a Master of Science in Counselling (ZOU), Bachelor of Science in Counselling (ZOU), Certificate in Systemic Therapy (CONNECT), Diploma in Secretarial Studies (PITMAN). Presently Ms Jura counsel, guide, supports students with different learning challenges, monitor at risk students and advocates for students in different situations.

Citation: FLORENCE JURA. "Marriage Discord and Social Media Platforms among Couples: A Case Study of One Selected High-Density Suburb in Marondera, Zimbabwe" International Journal of Humanities Social Sciences and Education (IJHSSE), vol 8, no. 4, 2021, pp. 63-71. doi: https://doi.org/10.20431/23490381.0804008.

Copyright: (1) 2021 Authors. This is an open-access article distributed under the terms of the Creative Commons Attribution License, which permits unrestricted use, distribution, and reproduction in any medium, provided the original author and source are credited. 